\title{
Increasing Perioperative Risk Scoring in Emergency Laparotomy: A Surgical Trainee-Led Nationwide Quality Improvement Programme
}

\section{Deirdre M Nally}

Royal College of Surgeons in Ireland https://orcid.org/0000-0001-8590-0021

Peter E Lonergan

Royal College of Surgeons in Ireland

Emer $\mathrm{P} O$ Connell

Beaumont Hospital

Deborah McNamara ( $\square$ deborahmcnamara@rcsi.com )

Royal College of Surgeons in Ireland

\section{Research}

Keywords: emergency laparotomy, quality improvement, risk assessment

Posted Date: April 5th, 2021

DOI: https://doi.org/10.21203/rs.3.rs-361191/v1

License: (9) This work is licensed under a Creative Commons Attribution 4.0 International License. Read Full License 


\section{Abstract}

Background: Emergency laparotomy is associated with high morbidity and mortality. The early identification of high-risk patients allows for the provision of timely perioperative care and appropriate resource allocation. The aim of this study was to develop a nationwide surgical trainee-led quality improvement (QI) programme to increase the use of perioperative risk scoring in emergency laparotomy.

Methods: The programme was structured using the active implementation framework in 15 state-funded Irish hospitals to guide the staged implementation of perioperative risk scoring. The primary outcome was a documented preoperative risk score for patients undergoing an emergency laparotomy at each site.

Results: The percentage of patients undergoing emergency laparotomy who received perioperative risk scoring increased from $0-11 \%$ during the exploratory phase to $35-100 \%$ during the full implementation phase. This change was consistently maintained throughout the full implementation phase of the programme.

Conclusions: A trainee-led QI programme increased the use of perioperative risk assessment in patients undergoing emergency laparotomy, suggesting that such an approach may be feasible for improving patient outcomes and care delivery performance.

\section{Contribution To The Literature}

- This study describes the structure and delivery of a successful QI programme to increase the use of perioperative risk scoring in emergency laparotomy

- This project illustrates how an active implementation framework can be applied to quality improvement projects in surgical care and the contextual considerations surrounding same.

- It demonstrates how trainees / residents are appropriately placed to develop networks and deliver national level quality improvement

\section{Introduction}

Emergency abdominal surgery encompasses a variety of high-risk intra-abdominal surgical procedures that require the timely delivery of resource-intensive care. In recent years surgical and anaesthetic improvement programmes have focused on emergency laparotomy as it is associated with significant morbidity and a 30-day mortality rate ranging from 5 to $21 \%(1-9)$. There are considerable differences among patients undergoing emergency laparotomy, not only in the indication for surgery $(9,10)$ and the presence of co-morbidities(11), but also in factors related to the delivery of care(12). Outcomes are worse for older, frail patients(13) as well as for patients from ethnic minorities, lower socioeconomic groups and those who are uninsured $(14,15)$. Although it is difficult to control for patient factors, evidence points to wide variability in the processes of the delivery of care $(4,12,16)$. Optimal care requires that the structure 
and delivery of perioperative care is tailored to the needs of the individual, so early identification of highrisk patients is a priority.

Assessment of a patient's risk of an adverse outcome may be informed by clinical judgement, risk assessment tools, biomarkers and evaluation of functional capacity(17). Whilst clinical judgement is important, it is not enough to predict adverse outcomes postoperatively(18). The utility of systematic preoperative assessment is emphasised by the findings of the UK National Emergency Laparotomy Audit (NELA) which found a 30-day mortality of 5.4\% among unassessed patients, compared to $16.9 \%$ and $1.6 \%$ respectively for those deemed high or low risk(18). Components of care delivery, such as consultant review before surgery, consultant presence in theatre and admission to the intensive care unit, may vary according to whether risk has been assessed and documented before surgery. Thus, pre-operative risk documentation before emergency laparotomy may be considered a surrogate marker of good quality care and where it is not done patients miss out on the standard-of-care.

A number of approaches to improving outcomes for patients undergoing emergency laparotomy have been described, including audit(18), peer comparison(9), best practice tariffs(18), 'name and shame' strategies(19) and local improvement activities(20). Facilitating frontline healthcare professionals to address key issues in their work area is a common low-cost strategy for delivering improvement $(21,22)$, but has recognised deficiencies, especially when such work happens in an uncoordinated way(23). Within the Irish healthcare system, surgical trainees (residents) are the primary frontline staff for surgical patients but they are frequently overlooked as agents for change and remain largely isolated from hospital-based improvement programmes due to the temporary nature of their positions. Postgraduate surgical trainees have limited training in QI methodology(24) and improvement programmes led by trainees are barely visible in the literature(25). Trainee involvement in improvement activities may be an effective strategy for developing a "local" culture of process improvement.

The aim of this study was to develop the structures to support a nation-wide surgical trainee-led quality improvement programme and evaluate interventions in the implementation to increase the use of perioperative risk scoring in laparotomy.

\section{Methods}

\section{Context}

State-funded health care in the Republic of Ireland (population 4.8 million) is available to all residents. It is organised and delivered by the Health Service Executive (HSE). State-funded hospitals are divided into 7 hospital groups with geographically defined catchment areas. Each group has at least one designated Cancer Centre and a number of other hospitals, classified into 4 levels (termed "models") with increasing complexity of care available at each level. Regarding acute surgical services, model 3 hospitals provide care to undifferentiated surgical patients; model 4 hospitals provide acute undifferentiated care and accept tertiary referrals(26). Twenty-four hospitals provide acute surgical services, each operating an on- 
call rota to provide emergency services on a 24-hour basis. Nationwide an average of 2,068 emergency laparotomies are performed annually(9).

General surgery training in Ireland is an 8-year structured postgraduate training pathway separated into a 2-year "core" surgical programme followed by competitive entry into a 6-year "specialty" training programme. General Surgery trainees (years 3-8) work across model 3 and 4 hospitals providing 24-hour emergency on-call cover in addition to a consultant general surgeon.

\section{Conceptual Framework}

This study was a prospective QI programme, called "Know The Score" involving 25 surgical trainees and 1 surgical physician associate working in 15 state-funded Irish hospitals. The programme was structured using the active implementation framework (AIF)(27) to guide the staged implementation of perioperative risk scoring for emergency laparotomy patients using plan-do-study-act cycles (PDSA). A distributed leadership model was utilised, combining local programme leads at individual sites supported by a central implementation team to provide competency, organisational and leadership support. The programme implementation team consisted of a senior surgical trainee (DMN) to provide near-peer clinical leadership, a post-specialty training fellow in QI in surgery (PEL) to deliver technical expertise and overall programme sponsorship was provided by a senior surgeon (DAMc) within the framework of the Irish National Clinical Programme in Surgery. Surgical trainees were voluntarily recruited in each hospital to lead the programme at local level and provided with structured coaching, mentorship and resources based on individual and local needs. The study was endorsed within the HSE National Quality Assurance \& Improvement System (NQAIS) Clinical Governance Framework and registered with the Audit/ QI Committee in the institution of the senior author, a university teaching hospital and national referral center. Data on individual hospitals were de-identified and presented in an anonymised fashion to ensure confidentiality at all stages of the analysis. No funding was received for this project and the authors have no conflicts of interest to disclose. This report complies with the SQUIRE 2.0 (Standards for QUality Improvement Reporting Excellence) guideline(28).

\section{Interventions}

Specific interventions were designed and tested based on AIF implementation stage: exploration, installation, initial implementation and full implementation(27) (Table 1). The initial exploration phase interventions included multiple presentations highlighting variation in outcomes after emergency laparotomy at national surgical meetings and an associated media campaign to raise awareness. Interventions in the installation stage included written correspondence to all hospital clinical directors and departmental chairs outlining the improvement programme, installation of posters with a quick response (QR) code to access risk scoring apps in participating hospitals, a participant-wide secure messaging group to support communication, dissemination of a standardized presentation slide set to support local programme education and a formal invitation to all current Irish surgical trainees to participate in the change initiative. During the initial implementation phase interventions consisted of twice-monthly teleconferences for local leads, local educational presentations on the programme given by programme 
participants and the bi-weekly distribution of the programme run-chart to as a means of "real-time" feedback. Trainees were supported to develop improvement cycles depending on the needs identified in their hospital. Performance data was shared internally in the hospital but routinely de-identified for national input.

\section{Evaluation of Interventions}

Programme participants completed a questionnaire during the initial implementation phase to evaluate their QI knowledge before and after the programme and to evaluate the effectiveness of the interventions used. A twelve-item questionnaire was designed using web-based survey software (Qualtrics ${ }^{T M}$, USA) and distributed to participants. Three baseline questions were designed to assess current scope of practice, prior experience in QI and understanding of QI prior to and during programme participation. Five multiple choice and ranked order questions were used to assess which programme interventions participants found valuable in driving change and could be adapted to their local practice. Four questions using a mixture of Likert scale and free text were used to capture the experiences of participants and feedback received from colleagues at local sites. Questionnaires were analysed using descriptive statistics, weighting of ranked responses to calculate highest average ranking and qualitative analysis of key themes from free-text responses.

\section{Programme communication}

Communication between local programme leads and the steering group took the form of email at commencement of involvement with the study, for dissemination of programme materials or to notify collaborators of key programme initiatives such as a participant survey. Phone calls were used at the discretion of the steering group to contact local leads. Routine communication between local programme leads and the steering group was conducted using the programme "WhatsApp" messaging group. The volume, content and temporal pattern of messages communicated in the programme instant messaging group between local leads and the steering group were recorded for the duration of the study and analysed as a proxy measurement of the engagement of local leads with the programme.

\section{Data collection and statistical analysis}

The primary outcome was a documented preoperative risk score for every patient undergoing an emergency laparotomy at each hospital site. De-identified data regarding laparotomy volume and risk scoring performance were submitted to the steering group using the "WhatsApp" platform at each biweekly data collection time-point. The volume of emergency laparotomies performed for biweekly data collection time-points was recorded for each study site to indicate site operative volume. The median value for average number of laparotomies per data collection was used to stratify study sites into "low" and "high" volume hospitals. Bi-weekly arithmetic means for patients who had a risk score performed at each site were deidentified, submitted centrally, plotted on a run-chart and shared with local study leads. A baseline was constructed for the first six data points during the exploration phase of the programme (from September 2018 to December 2018). The primary outcome was assessed for evidence of 
improvement using a Shewhart statistical process control chart (SPC). This technique was deemed most appropriate in the context of real-world large-scale change in which the control of independent variables is not always possible(29). The chart was then inspected for common cause variation (random fluctuation) and special cause variation (changes due to external factors). Special cause variation or a substantial change not due to natural variation was identified, either when the mean bi-weekly performance breached the upper or lower control limits or when eight consecutive bi-weekly performances lay on one side of the mean line. Special cause variation was considered a clinically and statistically significant change.

\section{Results}

\section{Performance of risk scoring}

A total of 26 surgical professionals in 15 hospitals were recruited into the programme. The grade of practice of participants is shown in Supplementary Table 1. Eight (53\%) Model 4 hospitals were and seven (47\%) Model 3 sites were included. The primary outcome measure was a documented preoperative risk score for patients undergoing an emergency laparotomy at each site. Data was plotted on a run-chart (Supplementary Figure 1). Over the 15-month period of data collection, two arbitrary targets were set $50 \%$ of reported cases scored by the end of month 5 (January 2019) and $70 \%$ of reported cases scored by the end of month 10 (June 2019). Within the exploration phase of the programme, the percentage of cases scored ranged from $0-11 \%$. The interventions in the installation phase (months 1-3) led to increase in the percentage of cases scored ranging from $8-35 \%$. The percentage of cases risk assessed in the initial implementation phase (months 4-6) ranged from $21-67 \%$. Within the full implementation phase from 6 months onwards, the percentage of cases scored ranged from $35-100 \%$. The interim targets of $50 \%$ of cases scored was achieved by the end of month 5 , however this was not sustained initially. Full implementation of the programme resulted in meeting the second interim target of $70 \%$ of cases scored. Full implementation was associated with a more consistent percentage of cases being scored throughout.

The primary outcome of percentage cases scored was also assessed for evidence of variability using an SPC chart (Figure 1). Within the setting of real-world change across multiple sites and contexts in which the control of external factors is impossible to control for, an SPC chart permitted variability to be assessed. Breach of the lower control limits indicating statistically significant change (special cause variation) was found at 3 points within the exploration and installation phases of the programme. Variation was reduced as the programme proceeded through the subsequent phases of implementation.

\section{Programme implementation at local study sites}

Study sites participated for a varying length of time in the programme (mean=12.4 months, $S D=4.66$ months). A minimum of six months was required for inclusion in the following data analysis. The mean number of data collection time points to which individual study sites submitted data was 16.1 (SD 5.5, range 7-24). The number of laparotomies reported by each site varied from 4 to 70 with a mean of 33.4 
$(S D=21.6)$. Operative volume at individual sites ranged from a mean of 0.44 to 4.12 laparotomies per data collection time-point. The proportion of laparotomies risk scored varied from 7-100\% for study sites. It was anticipated that the performance of risk scoring would increase in study sites with a longer duration of participation in the programme. However, there was no correlation between overall participation time of study sites and risk scoring performance $(r=-0.16, p=0.59)$.

The average proportion of laparotomies risk scored was higher in centres designated as "low" volume compared to "high volume" but this was not statistically significant (mean $=0.63 \vee 0.42, p=0.19$ )(Figure 2A). Similarly, an association was suggested between the number of local leads at a study site and the proportion of laparotomies risk scored (Figure 2B). Study sites with one local lead were most successful in performing risk scoring. The mean proportion of laparotomies scored in sites with one, two and three local leads was $0.76,0.38$ and 0.50 respectively $(p=0.07)$. These findings suggest that study sites with relatively lower operative volume and an individual QI lead may be more capable of effecting local change. Greater personal engagement and a sense of ownership of a QI project may be instrumental in effecting change while larger study sites may see effectiveness reduced by distribution of responsibility amongst local participants

\section{Programme communication}

Analysis of the volume, content and timing of messages within the programme WhatsApp group provides insight into the use of mobile instant messaging as a communication tool to effect change in QI. A large variation was observed in the number of messages sent within the group by individual local leads (mean=15.2, range $=1-64$ ). No significant difference was observed between trainee grades and messaging volume. A number of leads used the messaging service solely for submission of local data. Other local leads used the service to communicate their experience of the programme including success or failure of local initiatives or to suggest novel approaches to effect change.

The total number of messages sent by local leads in each study site was calculated to determine if messaging volume was correlated with success in risk scoring laparotomies. No correlation was observed between total communication volume from study sites and the total proportion of laparotomies scored $(r=0.02, p=0.95)$. The temporal pattern in mobile internet messaging amongst the steering group and local leads illustrates the variation in participant performance and engagement during the course of the programme (Figure 3). A surge in messaging activity was observed amongst steering group members and local leads at the key times such as programme commencement and approaching July 2019 changeover. Impact of messaging activity is also apparent with a peak in risk scoring performance seen to be preceded by increased message activity.

\section{Impact of rotation of local leads}

The contribution of individual hospitals to data collection was compared between hospital sites for the period January 2019 - July 2019 and July 2019 to December 2019. It was possible to compare data contribution in ten hospital sites during these periods (Supplementary Figure 2A). Eight out of ten study 
sites contributed to less of the available data collection timepoints following July 2019 rotation. Contribution to data collection time points was increased in one site following rotation while one site was unaffected by changeover. The impact of rotation on the performance of risk scoring was more positive (Supplementary Figure 2B). The average proportion of laparotomies risk scored was increased in six of ten study sites following July 2019. Risk score performance decreased in three sites following rotation while performance was unaffected in one site.

The engagement of local leads was reflected in the volume of messages communicated in the programme "WhatsApp" group before and after July 2019 (Supplementary Figure 3). A large degree of

variation was observed in messaging volume before and after the rotation with the majority of local leads sending higher numbers of messages prior to July 2019 perhaps suggesting programme fatigue amongst participants.

Overall, it appears that study sites contributed less regularly to data collection time-points after July 2019 rotation, but when data were submitted, they indicated increased performance of risk scoring. These findings may have a number of implications. The first is that enthusiasm for the programme may have waned following job rotations and consistent data collection and submission could not be maintained. Secondly, it is possible that local leads may have avoided submitting data which reflected low performance of risk scoring and preferentially submitted data at timepoints with better performance.

\section{Experience of programme participants}

The programme questionnaire was completed with an $88.5 \%$ response rate. $60.8 \%$ of participants had no prior experience or training in QI. 39.4\% of participants considered themselves to have "good" understanding of QI prior to commencing the programme, increasing to $94.1 \%$ after four month's participation. Participants reported that trainee teleconferences, reminder messages regarding data collection and visible display of programme goals in the hospital were most useful for driving change during the programme (Figure 4). Participants also highly valued the contribution of the programme to their professional logbook. When asked to describe the most effective local intervention, communication emerged as a key theme. Participants highly valued conducting the programme as a network of collaborators with frequent reminders and encouragement from colleagues on site as well as programme coordinators. Common themes of feedback to the programme highlighted a concern amongst surgical teams that the implementation of risk scoring would not alter clinical management. A frequent suggestion for programme improvement was the incorporation of risk scoring into standard preoperative documentation.

\section{Discussion}

This study describes the structure and implementation of a nationwide surgical trainee-led QI programme to increase the use of perioperative risk scoring in emergency laparotomy using the active implementation framework. Over the duration of the programme, the percentage of patients undergoing emergency laparotomy who received perioperative risk scoring increased from $0-11 \%$ during the 
exploratory phase to $35-100 \%$ during the full implementation phase. This change was consistently maintained throughout the full implementation phase of the programme.

Two large scale, prospective Emergency Laparotomy QI programmes from the UK have recently been published, from the Emergency Laparotomy Collaborative (ELC) group(30) and the Enhanced PeriOperative Care for High-Risk Patients (EPOCH) trial group(31). The ELC study involved the implementation of a 6-point care bundle in 28 National Health Service (NHS) hospitals and found a reduction in the unadjusted mortality rate and the length of stay as well as changes in some of the care bundle metrics. This programme used the Institute for Healthcare Improvement $(\mathrm{IHI})$ Breakthrough Series collaborative as an implementation framework. Although, perioperative risk assessment was not part of the care bundle, it demonstrated that QI methodology can improve outcomes in emergency laparotomy at scale(30). The EPOCH trial intervention consisted of an extensive 37-point evidence-based care pathway in 15,873 patients in $93 \mathrm{NHS}$ hospitals. Overall, the study investigators found that there were modest improvements in 10 patient-level process measures, however this did not translate to overall outcome measures including overall survival, 90 - and 180-day mortality, length of hospital stay or frequency of readmission(31). There were wide variations in intervention fidelity between hospitals, with differences in the processes that individual teams tried to change, the rate of change and the eventual success. In a hospital-level evaluation of the EPOCH trial, no hospital reliably implemented all 10 processes. Out of 93 participating hospitals, 80 provided sufficient data for analysis generating 800 process measure charts from 20,305 patient admissions over 27 months. Overall, only 279 of the 800 processes were improved(32). These findings show that change at scale and the context in which change is being implemented is far more complex than initially anticipated. Context is central to the success (or failure) of QI programmes.

Successful implementation is not only influenced by context but also by the content of the intervention and the process of implementation. A number of reports have been published on the effects of smallscale QI projects to improve outcomes in emergency laparotomy. The ELPQuicC group assessed the implementation of a bundle of 5 interventions in 4 hospitals and reported a reduction in risk-adjusted mortality (risk ratio $0.61,95 \%$ confidence interval $0.45-0.84)(20)$. The difference in findings compared to the $\mathrm{EPOCH}$ trial may relate to the simpler intervention, but also a stronger pre-existing relationships between staff leading implementation in these early adopter hospitals. The EPOCH trial set ambitious targets in hospitals in which there may have been a less favourable organisational readiness for change that in the ELPQuicC hospitals. Reports of QI programmes in other clinical areas have delivered mixed results(33-35), suggesting that more focused, discrete clinical interventions might be more successfully implemented than interventions that include a larger number of clinical processes.

A mixed-methods process evaluation of the planning, delivery and reception of the EPOCH intervention at hospital level found that fidelity of the intervention showed considerable variability across individual hospitals and only 11 of 37 care pathway processes that more than half of respondents reported attempting to improve(36). Analysis of the qualitative data for the trial suggests QI leads were often attempting to deliver the intervention in challenging contexts and identified barriers including the social 
aspects of change such as engaging colleagues, limited time, limited organizational resources and challenges in collecting data(36).

The model of trainee-led QI programmes are relatively sparse in the literature. There have been successful trainee-led programmes aimed at improving patient satisfaction(37), increasing compliance with venous thromboembolism prophylaxis(38), reducing opioid analgesia discharge prescriptions(39) and other programmes $(40,41)$. This study demonstrates that within a structured programme, surgical trainees can deliver improvement at a national level. Postgraduate surgical trainees in resource-limited healthcare systems are adaptable and resourceful and with the correct support an ideal group of healthcare professionals to drive change at local level. In addition, trainees are front line staff that have the potential to influence the intervention, engage staff and counteract resistance and suspicion about externally led change(42). In the context of limited organization resources and potentially challenging data collection, a simple, explicitly designed measure with data collection, monitoring and a feedback system incorporated into improvement activities from the outset. The primary outcome of a documented preoperative risk scoring was chosen as a balance between a credible measure by participants without being unduly burdensome, or difficult to interpret.

Adaptability and trialability is often essential in ensuring QI interventions can fit within different contexts and is a driver of success in our programme. However, fidelity to key parts of an intervention is also important to maximise the likelihood of success(43). Although fidelity was not directly assessed in our programme, it is likely there was considerable variability in the local implementation of the intervention and this may impact long term sustainability of improvements achieved.

Central to the success of the programme are the social aspects of improvement which are as likely to be as important as more technical aspects, such as data analysis and feedback. Similarly, a central expert implementation team oversaw the development of local programme teams building local QI capacity and serving as an accountable structure to move through the stages of implementation successfully. Local programme leads capitalised on social QI strategies to drive change through utilization of a participant messaging platform as well as the programme leadership through use of monthly participant teleconferences. Building and maintaining effective social relationships is time-consuming and challenging, particularly senior colleagues and hospital administration(44). This may be even more challenging for trainees who usually have temporary training appointments. Preoperative risk assessment is not a magic bullet. Developing consensus around the value of a formalised process of preoperative assessment required some to engage senior surgeons of the value of the selected intervention(45).

Given that this was an unfunded project, the resources and time available to coach local QI leads was limited in comparison to other reported QI interventions such as the IHI Breakthrough Series Collaborative model(46). Our programme was designed as a parsimonious intervention, with limited face-to-face meetings, so that it could be adapted and replicated widely if found to be successful. A higher intensity 
coaching programme might have led to greater intervention fidelity, however, it is uncertain if this is always the case $(47,48)$.

There are some inherent limitations to our study which need to be acknowledged. The primary outcome was a documented preoperative risk score for patients undergoing an emergency laparotomy at each site, however, we did not evaluate changes in patient outcomes associated with the intervention. Variations in the denominator for the bi-weekly measures sometimes interfered with signals in the data. For example, in a 2-week period with a small denominator, fewer patients scored may create a data point that breaks a signal that would otherwise indicate a move towards improvement. In combination with the time-bound nature of the analyses, this may have led to some real-world improvements not being identified using the run charts.

\section{Conclusions}

This programme describes the structure and implementation of a nationwide surgical trainee-led QI programme to increase the use of perioperative risk scoring in emergency laparotomy using the active implementation framework which demonstrated a sustained improvement in risk assessment during the full implementation phase. Such an approach may be feasible for improving patient outcomes and care delivery performance.

\section{Declarations}

- Ethics approval and consent to participate

The study was endorsed within the HSE National Quality Assurance \& Improvement System (NQAIS) Clinical Governance Framework and registered with the Audit and QI Committee in Beaumont Hospital (CA860), the hospital of the Senior Author and one of the Royal College of Surgeons of Ireland Hospital Group Hospitals. No patient information was collected. Data on individual hospitals were de-identified and presented in an anonymised fashion to ensure confidentiality at all stages of the analysis. No funding was received for this project.

\section{- Consent for publication}

This manuscript does not contain any individual person's data which would require consent for publication. All Authors consent for publication of the manuscript as submitted

\section{- Availability of data and materials}

Not applicable: Data sharing is not applicable to this article as no datasets were generated or analysed during the current study.

- Competing interests 
The authors declare that they have no competing interests.

\section{- Funding}

No funding was received for this project

\section{- Authors' contributions}

SURGical Improvement Network (SURGIN) is a group of surgeons and surgical Trainees in the Republic of Ireland who have an interest in Quality Improvement in Surgery. The group consists of a core group consisting of a steering committee and advisory group and local collaborators. The senior author of this paper is the overall lead and can be emailed at deborahmcnamara@rcsi.ie

DN was part of the Steering Committee/ Writing Group/ Data Analysis / Advisory Groups for the project. She was also a local lead.

PL was part of the Steering Committee/ Writing Group/ Data Analysis / Advisory Groups for the project.

EOC was part of the Steering Committee/ Writing Group/ Data Analysis / Advisory Groups for the project. She was also a local lead

DMcN was part of the Steering Committee/ Writing Group/ Data Analysis / Advisory Groups for the project.

All authors read and approved the final manuscript

DN and PL contributed equally and hence should have joint first authorship.

This project was a collaboration and we wish to recognise all contributions such that they are each cited on pubmed in accordance with established, published protocols which are linked to ICMJE guidelines. The collaborators listed below performed as essential local leads and local collaborators.

Sami Abd Elwahab, Gary Bass, Eoghan Burke, David Cagney, Angela Canas, Cathy Cronin, Carolyn Cullinane, Liam Devane, Naomi Fearon, Amy Fowler, Anna Fullard, Daniel Hechtl, Michael Kelly, John Lenihan, Edward Murphy, Deirdre Nally, Colm Neary, Emer O'Connell, Robert O'Connell, Maeve O Neill, Chrisen Ramkaran, Alexandra Troy, Roisin Tully, Christopher White, Himanshu Yadav,

\section{- Acknowledgements}

As above, we wish to acknowledge the contribution of the collaborators such that the names of the individual members of the Group will be searchable through their individual PubMed records

\section{References}


1. Al-Temimi MH, Griffee M, Enniss TM, et al. When is death inevitable after emergency laparotomy? Analysis of the American College of Surgeons National Surgical Quality Improvement Program database. Journal of the American College of Surgeons 2012;215(4):503-11. doi: 10.1016/j.jamcollsurg.2012.06.004 [published Online First: 2012/07/14]

2. Tan BHL, Mytton J, Al-Khyatt W, et al. A Comparison of Mortality Following Emergency Laparotomy Between Populations From New York State and England. Annals of surgery 2017;266(2):280-86. doi: 10.1097/sla.0000000000001964 [published Online First: 2016/08/23]

3. Saunders DI, Murray D, Pichel AC, et al. Variations in mortality after emergency laparotomy: the first report of the UK Emergency Laparotomy Network. British journal of anaesthesia 2012;109(3):368-75. doi: 10.1093/bja/aes165 [published Online First: 2012/06/26]

4. Symons NR, Moorthy K, Almoudaris AM, et al. Mortality in high-risk emergency general surgical admissions. Br J Surg 2013;100(10):1318-25. doi: 10.1002/bjs. 9208 [published Online First: 2013/07/19]

5. Vester-Andersen M, Lundstrom LH, Moller MH, et al. Mortality and postoperative care pathways after emergency gastrointestinal surgery in 2904 patients: a population-based cohort study. British journal of anaesthesia 2014;112(5):860-70. doi: 10.1093/bja/aet487 [published Online First: 2014/02/13]

6. Tengberg LT, Cihoric M, Foss NB, et al. Complications after emergency laparotomy beyond the immediate postoperative period - a retrospective, observational cohort study of 1139 patients. Anaesthesia 2017;72(3):309-16. doi: 10.1111/anae.13721 [published Online First: 2016/11/04]

7. Broughton KJ, Aldridge O, Pradhan S, et al. The Perth Emergency Laparotomy Audit. 2017 doi: 10.1111/ans. 14208

8. Stevens CL, Brown C, Watters DAK. Measuring Outcomes of Clinical Care: Victorian Emergency Laparotomy Audit Using Quality Investigator. World J Surg 2018;42(7):1981-87. doi: 10.1007/s00268-017-4418-4 [published Online First: 2017/12/29]

9. Nally DM, Sorensen J, Valentelyte G, et al. Volume and in-hospital mortality after emergency abdominal surgery: a national population-based study. BMJ Open 2019;9(11):e032183. doi: 10.1136/bmjopen-2019-032183 [published Online First: 2019/11/05]

10. Nally DM, Sorensen J, Kavanagh DO. Emergency laparotomy research methodology: A systematic review. The surgeon : journal of the Royal Colleges of Surgeons of Edinburgh and Ireland 2019 doi: 10.1016/j.surge.2019.06.003 [published Online First: 2019/07/28]

11. Parmar KL, Law J, Carter B, et al. Frailty in Older Patients Undergoing Emergency Laparotomy: Results From the UK Observational Emergency Laparotomy and Frailty (ELF) Study. Annals of surgery 2019 doi: 10.1097/sla.0000000000003402 [published Online First: 2019/06/13]

12. Columbus AB, Morris MA, Lilley EJ, et al. Critical differences between elective and emergency surgery: identifying domains for quality improvement in emergency general surgery. Surgery 2018;163(4):832-38. doi: 10.1016/j.surg.2017.11.017 [published Online First: 2018/01/15]

13. Mclsaac DI, Moloo H, Bryson GL, et al. The Association of Frailty With Outcomes and Resource Use After Emergency General Surgery: A Population-Based Cohort Study. Anesthesia and analgesia 
2017;124(5):1653-61. doi: 10.1213/ane.0000000000001960 [published Online First: 2017/04/22]

14. Shahan $\mathrm{CP}$, Bell T, Paulus $\mathrm{E}$, et al. Emergency general surgery outcomes at safety net hospitals. The Journal of surgical research 2015;196(1):113-7. doi: 10.1016/j.jss.2015.02.044 [published Online First: 2015/03/26]

15. Shah AA, Haider AH, Zogg CK, et al. National estimates of predictors of outcomes for emergency general surgery. The journal of trauma and acute care surgery 2015;78(3):482-90; discussion 90-1. doi: 10.1097/ta.0000000000000555 [published Online First: 2015/02/25]

16. Smith M, Hussain A, Xiao J, et al. The importance of improving the quality of emergency surgery for a regional quality collaborative. Annals of surgery 2013;257(4):596-602. doi:

10.1097/SLA.0b013e3182863750 [published Online First: 2013/03/09]

17. Moonesinghe SR, Mythen MG, Grocott MP. Patient-related risk factors for postoperative adverse events. Curr Opin Crit Care 2009;15(4):320-7. doi: 10.1097/MCC.0b013e32832e067c [published Online First: 2009/06/11]

18. Audit NEL. Fifth Patient Report of the National Emergency Laparotomy Audit 2018 [Available from: https://www.nela.org.uk/downloads/The\%20Fifth\%20Patient\%20Report\%20of\%20the\%20NELA\%20\%20Highlight\%20Report.pdf.

19. Mittman BS. CReating the evidence base for quality improvement collaboratives. Annals of Internal Medicine 2004;140(11):897-901. doi: 10.7326/0003-4819-140-11-200406010-00011

20. Huddart S, Peden CJ, Swart M, et al. Use of a pathway quality improvement care bundle to reduce mortality after emergency laparotomy. Br J Surg 2015;102(1):57-66. doi: 10.1002/bjs.9658 [published Online First: 2014/11/12]

21. McNamara DA, Rafferty P, Fitzpatrick F. An improvement model to optimise hospital interdisciplinary learning. International journal of health care quality assurance 2016;29(5):550-8. doi:

10.1108/ijhcqa-10-2015-0131 [published Online First: 2016/06/04]

22. Gardam M, Gitterman L, Rykert L, et al. Five years of Experience using Front-Line Ownership to Improve Healthcare Quality and Safety. Healthc Pap 2017;17(1):8-23. doi:

10.12927/hcpap.2017.25339 [published Online First: 2017/12/27]

23. Dixon-Woods M, Pronovost PJ. Patient safety and the problem of many hands. BMJ Qual Saf 2016;25(7):485-8. doi: 10.1136/bmjqs-2016-005232 [published Online First: 2016/02/26]

24. Medbery RL, Sellers MM, Ko CY, et al. The unmet need for a national surgical quality improvement curriculum: a systematic review. J Surg Educ 2014;71(4):613-31. doi: 10.1016/j.jsurg.2013.12.004 [published Online First: 2014/05/13]

25. Patow CA, Karpovich K, Riesenberg LA, et al. Residents' engagement in quality improvement: a systematic review of the literature. Acad Med 2009;84(12):1757-64. doi: 10.1097/ACM.0b013e3181 bf53ab [published Online First: 2009/11/27]

26. Mealy K, Keane F, Kelly P, et al. What is the future for General Surgery in Model 3 Hospitals? Irish journal of medical science 2017;186(1):225-33. doi: 10.1007/s11845-016-1545-0 [published Online First: 2017/01/06] 
27. Fixsen DL, Naoom SF, Blase KA, et al. Implementation research: a synthesis of the literature. 2005

28. Ogrinc G, Davies L, Goodman D, et al. SQUIRE 2.0 (Standards for QUality Improvement Reporting Excellence): revised publication guidelines from a detailed consensus process. BMJ Qual Saf 2016;25(12):986-92. doi: 10.1136/bmjqs-2015-004411 [published Online First: 2015/09/16]

29. Baker AW, Haridy S, Salem J, et al. Performance of statistical process control methods for regional surgical site infection surveillance: a 10-year multicentre pilot study. BMJ Qual Saf 2018;27(8):60010. doi: 10.1136/bmjqs-2017-006474 [published Online First: 2017/11/28]

30. Aggarwal G, Peden CJ, Mohammed MA, et al. Evaluation of the Collaborative Use of an EvidenceBased Care Bundle in Emergency Laparotomy. JAMA Surg 2019;154(5):e190145. doi:

10.1001/jamasurg.2019.0145 [published Online First: 2019/03/21]

31. Peden CJ, Stephens T, Martin G, et al. Effectiveness of a national quality improvement programme to improve survival after emergency abdominal surgery (EPOCH): a stepped-wedge cluster-randomised trial. Lancet 2019;393(10187):2213-21. doi: 10.1016/S0140-6736(18)32521-2 [published Online First: 2019/04/30]

32. Stephens TJ, Peden CJ, Haines R, et al. Hospital-level evaluation of the effect of a national quality improvement programme: time-series analysis of registry data. BMJ Qual Saf 2019 doi: 10.1136/bmjqs-2019-009537 [published Online First: 2019/09/14]

33. Bion J, Richardson A, Hibbert P, et al. 'Matching Michigan': a 2-year stepped interventional programme to minimise central venous catheter-blood stream infections in intensive care units in England. BMJ Qual Saf 2013;22(2):110-23. doi: 10.1136/bmjqs-2012-001325 [published Online First: 2012/09/22]

34. Pannick S, Athanasiou T, Long SJ, et al. Translating staff experience into organisational improvement: the HEADS-UP stepped wedge, cluster controlled, non-randomised trial. BMJ Open 2017;7(7):e014333. doi: 10.1136/bmjopen-2016-014333 [published Online First: 2017/07/20]

35. Williams L, Daggett $V$, Slaven JE, et al. A cluster-randomised quality improvement study to improve two inpatient stroke quality indicators. BMJ Qual Saf 2016;25(4):257-64. doi: 10.1136/bmjqs-2015004188 [published Online First: 2015/08/26]

36. Stephens TJ, Peden CJ, Pearse RM, et al. Improving care at scale: process evaluation of a multicomponent quality improvement intervention to reduce mortality after emergency abdominal surgery (EPOCH trial). Implement Sci 2018;13(1):142. doi: 10.1186/s13012-018-0823-9 [published Online First: 2018/11/15]

37. Kiger ME, Bertagnoli T. A Project-Based, Resident-Led Quality Improvement Curriculum Within a Pediatric Continuity Clinic. MedEdPORTAL 2018;14:10738. doi: 10.15766/mep_2374-8265.10738 [published Online First: 2019/02/26]

38. Hussain SA, Arsene C, Hamstra C, et al. Successful Resident Engagement in Quality Improvement: The Detroit Medical Center Story. J Grad Med Educ 2016;8(2):214-8. doi: 10.4300/JGME-D-1500316.1 [published Online First: 2016/05/12] 
39. Bongiovanni T, Hansen K, Lancaster E, et al. Adopting best practices in post-operative analgesia prescribing in a safety-net hospital: Residents as a conduit to change. Am J Surg 2020;219(2):299303. doi: 10.1016/j.amjsurg.2019.12.023 [published Online First: 2020/01/14]

40. Miller $\mathrm{N}$, MacNew $\mathrm{H}$, Nester J, et al. Jump starting a quality and performance improvement initiative to meet the updated ACGME guidelines. J Surg Educ 2013;70(6):758-68. doi:

10.1016/j.jsurg.2013.06.016 [published Online First: 2013/11/12]

41. Shaikh U, Natale JE, Nettiksimmons J, et al. Improving pediatric health care delivery by engaging residents in team-based quality improvement projects. Am J Med Qual 2013;28(2):120-6. doi: 10.1177/1062860612448927 [published Online First: 2012/06/28]

42. Gollop R, Whitby E, Buchanan D, et al. Influencing sceptical staff to become supporters of service improvement: a qualitative study of doctors' and managers' views. Qual Saf Health Care 2004;13(2):108-14. doi: 10.1136/qshc.2003.007450 [published Online First: 2004/04/08]

43. Carroll C, Patterson $\mathrm{M}$, Wood $\mathrm{S}$, et al. A conceptual framework for implementation fidelity. Implement Sci 2007;2:40. doi: 10.1186/1748-5908-2-40 [published Online First: 2007/12/07]

44. Spurgeon P, Mazelan PM, Barwell F. Medical engagement: a crucial underpinning to organizational performance. Health Serv Manage Res 2011;24(3):114-20. doi: 10.1258/hsmr.2011.011006 [published Online First: 2011/08/16]

45. Dixon-Woods M, McNicol S, Martin G. Ten challenges in improving quality in healthcare: lessons from the Health Foundation's programme evaluations and relevant literature. BMJ Qual Saf 2012;21(10):876-84. doi: 10.1136/bmjqs-2011-000760 [published Online First: 2012/05/01]

46. Mills PD, Weeks WB. Characteristics of successful quality improvement teams: lessons from five collaborative projects in the VHA. Jt Comm J Qual Saf 2004;30(3):152-62. doi: 10.1016/s15493741(04)30017-1 [published Online First: 2004/03/23]

47. Pannick S, Sevdalis N, Athanasiou T. Beyond clinical engagement: a pragmatic model for quality improvement interventions, aligning clinical and managerial priorities. BMJ Qual Saf 2016;25(9):71625. doi: 10.1136/bmjqs-2015-004453 [published Online First: 2015/12/10]

48. Power M, Tyrrell PJ, Rudd AG, et al. Did a quality improvement collaborative make stroke care better? A cluster randomized trial. Implement Sci 2014;9(1):40. doi: 10.1186/1748-5908-9-40 [published Online First: 2014/04/03]

\section{Table}


Table 1.

Interventions by implementation phase

\begin{tabular}{|c|c|c|c|}
\hline $\begin{array}{l}\text { Exploration } \\
\text { (Pre-Intervention) }\end{array}$ & $\begin{array}{l}\text { Installation } \\
\text { (Months 1-3) }\end{array}$ & $\begin{array}{l}\text { Initial Implementation } \\
\text { (Months 4-6) }\end{array}$ & $\begin{array}{l}\text { Full } \\
\text { Implementation } \\
\text { (> } 6 \text { months) }\end{array}$ \\
\hline $\begin{array}{l}\text { Presentations on } \\
\text { emergency laparotomy } \\
\text { outcomes at national } \\
\text { surgical meeting }\end{array}$ & $\begin{array}{l}\text { Communication to } \\
\text { hospital clinical directors, } \\
\text { departmental chairs } \\
\text { describing programme }\end{array}$ & $\begin{array}{l}\text { Participant-wide } \\
\text { monthly } \\
\text { teleconferences }\end{array}$ & $\begin{array}{l}\text { Participant } \\
\text { certificate for } \\
\text { training } \\
\text { portfolio/logbook }\end{array}$ \\
\hline $\begin{array}{l}\text { Media coverage of } \\
\text { emergency laparotomy }\end{array}$ & $\begin{array}{l}\text { Programme theatre } \\
\text { posters with QR code to } \\
\text { access scoring apps }\end{array}$ & $\begin{array}{l}\text { Local presentations } \\
\text { (Grand Rounds, } \\
\text { anaesthetics, } \\
\text { perioperative nursing) }\end{array}$ & $\begin{array}{l}\text { Support for local } \\
\text { leads rotating } \\
\text { posts. }\end{array}$ \\
\hline $\begin{array}{l}\text { Creation of mobile } \\
\text { messaging group }\end{array}$ & $\begin{array}{l}\text { Email invitation to all } \\
\text { surgical trainees to } \\
\text { participate }\end{array}$ & $\begin{array}{l}\text { Bi-weekly progress } \\
\text { feedback }\end{array}$ & $\begin{array}{l}\text { Recruitment of } \\
\text { new local leads }\end{array}$ \\
\hline $\begin{array}{l}\text { Creation of data } \\
\text { analysis files }\end{array}$ & $\begin{array}{l}\text { Recruitment of study sites } \\
\text { encouraged through } \\
\text { steering group and local } \\
\text { lead contacts }\end{array}$ & $\begin{array}{l}\text { Reminder messages } \\
\text { for on-call doctors }\end{array}$ & $\begin{array}{l}\text { Quality } \\
\text { improvement } \\
\text { education } \\
\text { session }\end{array}$ \\
\hline $\begin{array}{l}\text { Baseline data collection } \\
\text { at limited study sites }\end{array}$ & $\begin{array}{l}\text { Programme slide } \\
\text { presentation for education } \\
\text { sessions by local leads }\end{array}$ & $\begin{array}{l}\text { Frequent } \\
\text { communication to } \\
\text { encourage local lead } \\
\text { discussion and } \\
\text { feedback }\end{array}$ & $\begin{array}{l}\text { Survey of } \\
\text { participant } \\
\text { experience }\end{array}$ \\
\hline
\end{tabular}

\section{Figures}




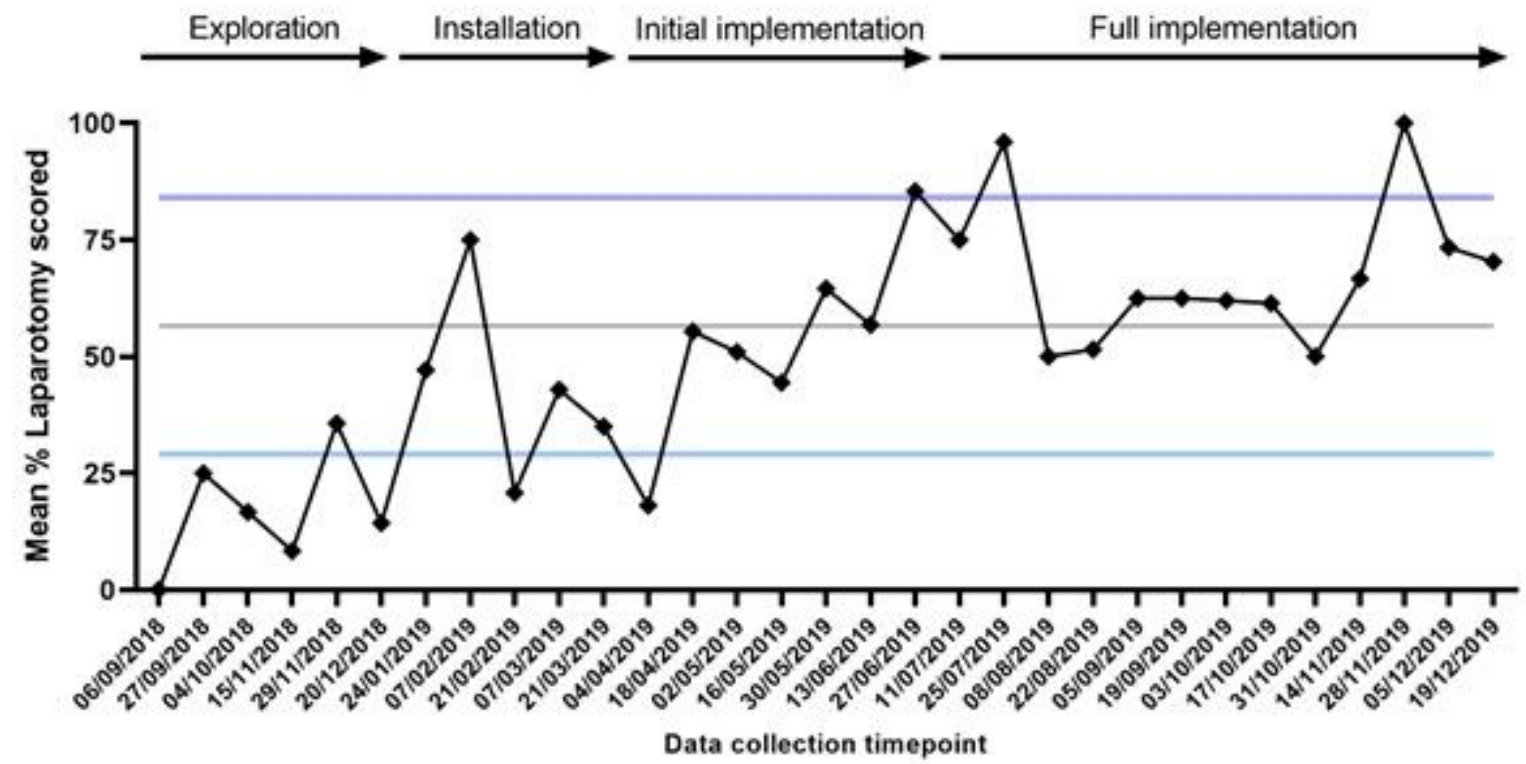

- Mean \% laparotomy scored per timepoint

- Mean \% laparotomy scored per project

- Lower Control Limit

- Upper Control Limit

\section{Figure 1}

Programme Statistical Process Chart

(A)

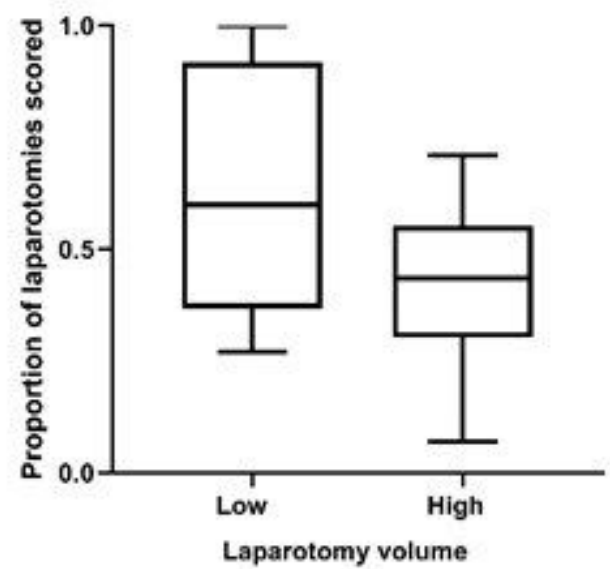

(B)

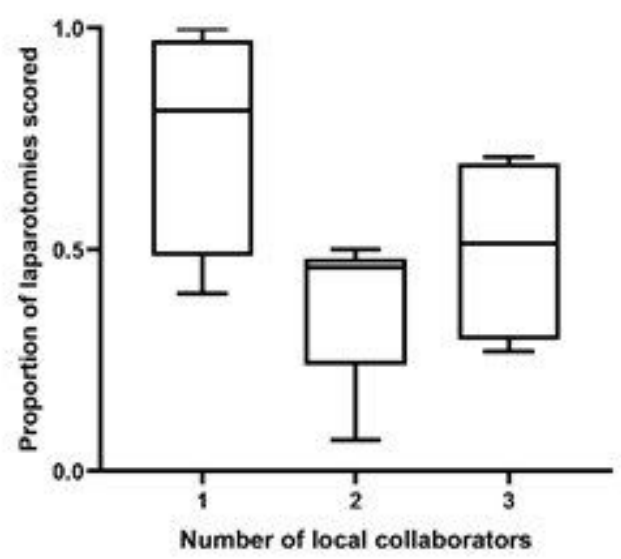

Figure 2 
Proportion of laparotomies risk scored according to study site factors. (A) Volume of laparotomies performed and (B) Number of local programme leads

\section{Risk score performance and project communication}

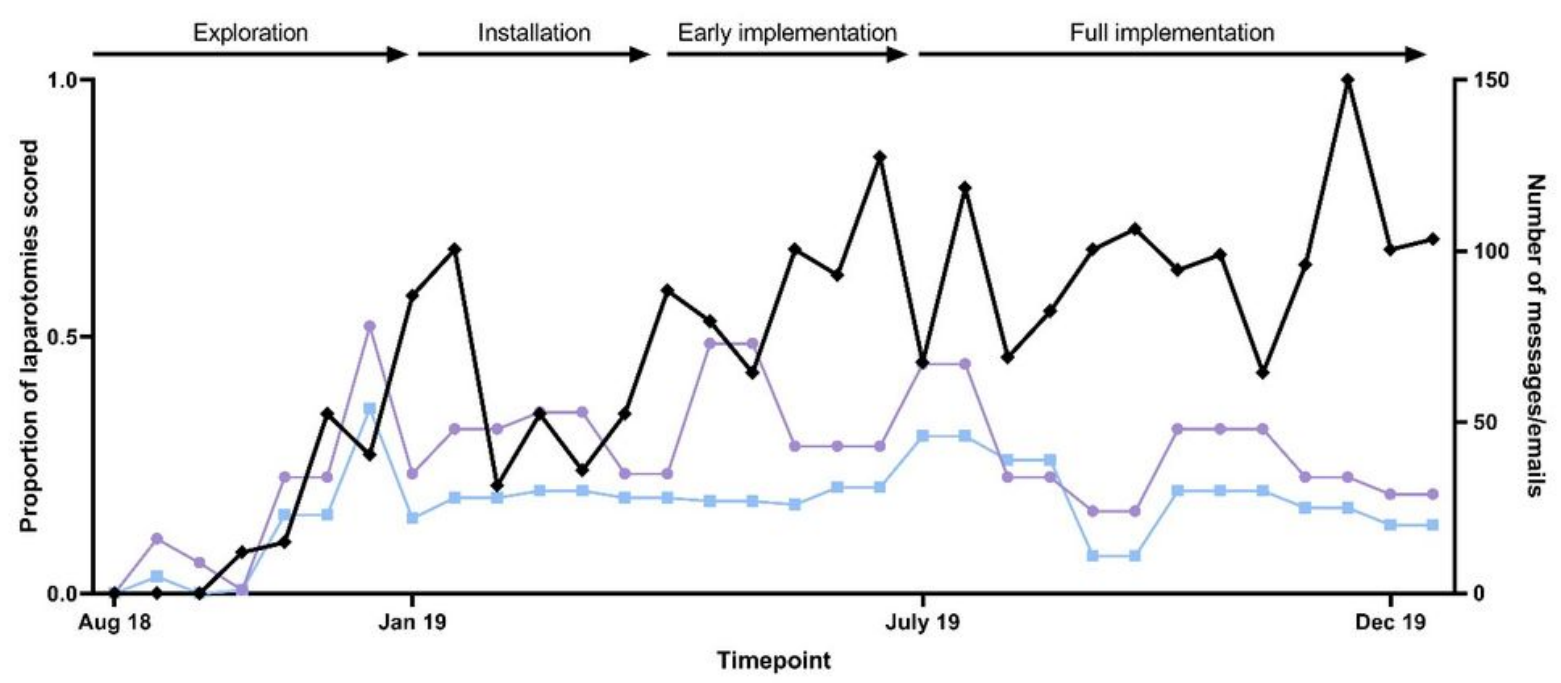

$$
\begin{aligned}
& \rightarrow \text { Proportion of laparotomies risk scored } \\
& - \text { Steering group instant messsages + emails } \\
& - \text { - Local collaborator instant messages + emails }
\end{aligned}
$$

\section{Figure 3}

Temporal relationship of risk score performance and volume of mobile instant messaging per month Importance of project interventions

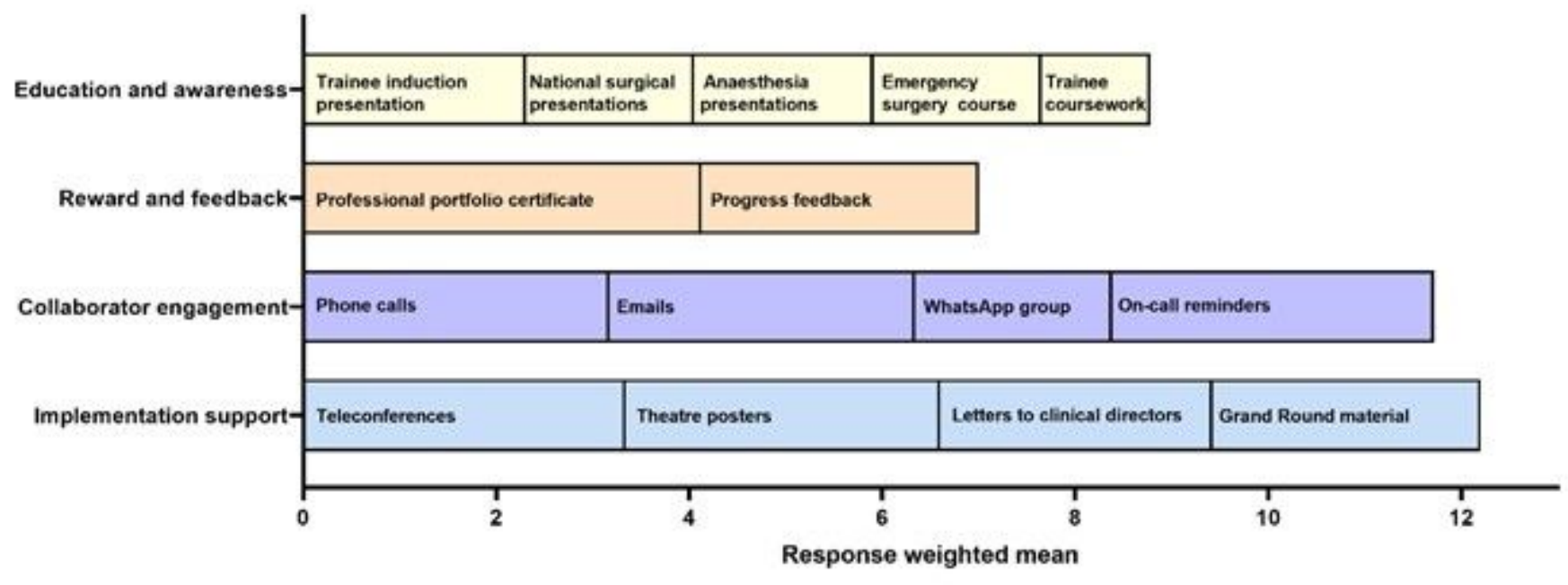

\section{Figure 4}

Importance of programme interventions ranked by participants 


\section{Supplementary Files}

This is a list of supplementary files associated with this preprint. Click to download.

- SQUIREELQI.docx

- Supplementarylnformation.docx 